\title{
Value-Based Communication during Covid-19 Pandemic: A Study on the Twitter Messages of Turkish Ministry of Health
}

\begin{abstract}
By Seda Mengu ${ }^{*}$, Murat Mengu ${ }^{ \pm}$\& Kemal Gunay
Influencing the whole world by obliging people to change their daily practices along with their relations and assume different life styles, Covid-19 has brought about some likely deleterious effects in Turkey as well. Undoubtedly, it has caused disturbance and even panic in social and psychological sense. In such cases of uncertainty and panic, communication with the public should be clear, explicit, alleviating and to some extent, guiding. People can be guided and convinced more easily if the level of distress and uncertainty decreases. Such a way of governing and compelling communication consists of different directions, requirements and combined effort. If co-operation is appropriately based on values, this process will be much easier. To that end, public discourse during the outbreak of the pandemic in 2019 was as successful as it was based on the daily life and language of society. Noteworthy, there are similarities between value-based collaboration and governmentality. Policies, customs, patterns and guidelines help maintain control and guidance over collaboration. At this point cooperation acts as a matter of participating in language games that build social and organisational realities that are created, debated, distributed and changed by means of mutual action and cooperation. The purpose of this study is to analyse the messages sent by the Ministry of Health during the pandemic in Turkey via social media, particularly Twitter, in order to find out to which extent these messages encompass the features of value-based communication. Thus, discourse analysis and descriptive research model are going to be implemented together. More specifically, the first tweet in which Corona was first referred was sent on January 25, 2020 and from then on 505 Tweets were posted. For the discourse analysis, 100 tweets that have received the most interaction are going to be used. As for the other descriptive analyses; on the other hand, all 505 tweets are going to be utilized in cluster analysis.
\end{abstract}

Keywords: value-based communication, discourse, social media, pandemic

\section{Introduction}

Covid-19 pandemic, which has produced dramatic consequences all over the world including Turkey, has also brought about some psychological and behavioural problems along with biological ones. What has spread is not only the virus but also some psychological disorders triggered by social trauma, such as excessive phobic reactions, depression, panic and paranoia as well as disruptive behavioural disorders, for instance selfishness, impulsivity selfishness, aggression and stigmatisation. In extraordinary situations people may temporarily lose their

*Professor, Head, Public Relations and Publicity Department, Faculty of Communication, Istanbul University, Turkey.

${ }^{ \pm}$Associate Professor, Head, New Media and Communication Department, Faculty of Communication, Istanbul Arel University, Turkey.

${ }^{*}$ PhD Researcher, Public Relations and Publicity Department, Faculty of Communication, Istanbul University, Turkey. 
ethical values such as common sense, empathy, co-operation etc. and turn to an egotist creature. That is why, the psychological atmosphere created by pandemics spread faster than the virus itself and affect even those who have a low risk of catching it. Hence, a pandemic brings along an intrinsic psychological state. It can be considered as an aggression proved by the fear of death. Individuals who have become apprehensive and selfish tend to get rid of the ones who pose a threat and guarantee their well-being. Another problem that is observed in epidemics and pandemics is stigmatisation. Major cholera and plague epidemics throughout history have been collective traumas for humankind. Therefore, people have always been scared of such epidemics and thus, tended to ostracise and even eradicate the patients. Although the attitude today is not so cruel, it can be suggested that the respective Covid-19 has caused some sort of stigmatisation.

Covid-19 has also caused some harmful effects in Turkey by bringing about disturbance and even panic in social and psychological sense. In such cases of uncertainty and panic, communication with the public should be clear, explicit, alleviating and to some extent, guiding. People can be guided and persuaded more easily with regard to the increase or reduction of anxiety and ambiguity. Such a leading and persuasive communication consists of various rules, regulations and collaborations. In value-based collaboration, this process will be managed more easily. Thus, discourses towards the public during the outbreak of pandemic have been performed to maintain value-based collaboration. This approach has proved to be successful as it has been based on daily life and the language of society. According to Foucault (qtd. in Jørgensen, 2004) value-based collaboration as a new form of governance resembles governmentality. Collaboration is controlled and guided by a set of rules such as procedures, traditions, norms and standards. Moreover, collaboration functions as a matter of participating in language games through which social and organizational realities are structured (Adolpsen and Norreklit, qtd. in Jørgensen, 2004: 87). In other words, organizational and social realities are formed, negotiated, shared and changed through interaction and collaboration. In fact, collaboration enables people not only to communicate, but also maintain mutual understanding and perform daily life practices (Silverman and Jones qtd in Jørgensen, 2004). Value-based communication generally consists of being people oriented, quality, participation, sustainable communication, trust, transparency, conformity with ethical standards, continual research, susceptibility to needs, qualitative and quantitative as well as continuing education etc.

One of the two significant concepts in this study is value-based collaboration. Thus, with regard to the pandemic, whether or not value-based collaboration has been achieved and people have been led effectively with the language used is examined. In accordance with value-based collaboration, the second important concept is value-based communication. Within the context of this study, the main criteria and sub-categories of value-based communication have been determined as follows: 


\section{Main Criterion: Governance}
a) Participation of stakeholders into the process/katılımc1lik.
b) Clarity.
c) Transparency.
d) Accountability.

II. Main Criterion: Trust
a. Providing continuous information/feedback.
b. Giving Priority to Quality/Quality in Healthcare.
c. Reciprocity.
d. Dialogue.
e. Interaction.
f. Assuming Responsibility.
g. Conformity with Ethical Standards.

III. Main Criterion: Actions Pertaining to People Oriented Health Care:
a. Meeting the Needs.
b. Qualified Health Care Personnel.
c. Quick Response.
d. Early Diagnosis.
e. Research (developing vaccination etc.)
f. Providing education to patients, doctors and whole society about the pandemic.
g. Value Based on Distribution: Equal Distribution of Resources to All Patient Groups.
h. Technical Value: Optimum Output with Available Sources.
i. Personal Value: Proper Care for the Fulfillment of Patients' Expectations.
j. Social Value: Contribution of Health Services to Social Participation and Connectedness (European Union, 2019).

All in all, the purpose of this study is to analyse the messages sent by the Ministry of Health during the pandemic in Turkey via social media, particularly Twitter, in order to find out to which extent these messages encompass the features of value-based communication. Thus, discourse analysis and descriptive research model have been implemented together. More specifically, the first tweet in which Corona was first referred was sent on January 25, 2020 and from then on 505 Tweets were posted. For the discourse analysis, 100 tweets that have received the most interaction are going to be used. As for the other descriptive analyses; on the other hand, all 505 tweets are going to be utilized in cluster analysis. 


\section{Literature Review}

\section{Value-Based Communication during the Pandemic Process}

In this study, a review was carried out on whether the nature of messages sent by the Turkish Minister of Health to communities through Twitter was in accordance with value-based communication. First of all, the main and sub-criteria of value-based communication have been determined and the concepts and discourses that set these criteria have been analyzed. Social media's new community creation and community management issues are important here. Social media is one of the tools used to gather people together around specific issues and get them moving in a certain direction. Social media has become one of the new social capital building tools.

As Szecsi and Koller (2017: 18) stated, the essence of social capital of community is the trust among individuals which enables a community to accomplish more with individuals' physical and mental capacities than they can achieve alone. In other words, social capital of community can be considered as an ability of individuals to cooperate for common communal objectives, which is influenced by social interaction and communication, relations of trust, communal norms and values. In this way, social networks of the individuals are formed.

Social media, as a social network area, also provides a share of various norms and values. Messages sent through Twitter during the pandemic process are created to increase the ability of individuals to collaborate for common goals in society. Discarded messages are aimed at demonstrating the importance of pandemic, what needs to be done, the risks, the measures that need to be taken, and motivating their cooperation on communities.

It is claimed that the best communities are indeed the hybrids of physical and virtual communities (Etzioni, 2001, Haythornthwaite and Kendall, 2010 qtd. in Szecsi and Koller, 2017: 20). In these new, hybrid forms of communities, virtual communities enhance physical communities. In this context, the boundaries between real and virtual forms of communities gradually get obscure, and individuals regard their virtual community as real. In the digital age, the function of communication as value-based in virtual communities also functions to create physical communities as well (ibid).

In a study conducted to find out the immediate impact of the Covid-19 pandemic on mental health and quality of life among local Chinese residents aged 18 and older in Liaoning Province, mainland China, Zhang and Ma (2020) circulated an online survey through a social media platform between January and February 2020. Participants completed a modified validated questionnaire that assessed the Impact of Event Scale (IES), indicators of negative mental health impacts, social and family support, and mental health-related lifestyle changes. Zhang and Ma have concluded that the Covid-19 pandemic was associated with mild stressful impact in their sample, even though the Covid-19 pandemic is still ongoing.

A new type of coronavirus (Covid-19) has caused physiological as well as psychological and behavioural problems. Bahadır (2020) lists the effects of the 
global epidemic on the psychology of individuals as follows: "An individual's personality, age, socio-economic-cultural level, skills to cope with stress, values, philosophy of life, etc. depends on many factors. Fear of illness and death are the primary factors during an epidemic where uncertainty prevails. People are worried about the illness along with the death of themselves and of their relatives. They also want to maintain their strength, graduate from school, make a living and protect themselves from getting sick. Naturally, anxiety may increase if solutions to these issues are not created, for example, if they are furloughed in this process. Unnecessary and inaccurate information can increase anxiety and fear. A new lifestyle has begun to emerge, especially due to the processes of staying home. Needless to say, human is a social being. For this reason, the sense of restriction and isolation caused by lockdown can make one feel emotionally under pressure. Other factors that cause anxiety during the pandemic can be reduced by practising the following:

- To be informed about the correct sources of disease and virus protection.

- To learn and apply what needs to be done about hygiene

- Unnecessary and inaccurate information can increase anxiety and fear.

- Accessing the right information sources and making use of them.

- Limiting the time spent on social media.

- Creating a daily routine may bring about the feeling that life continues in its normal course. Sleep, nutrition, work, etc. schedule can be designed. However, if trying to comply with this program is also a problem, a more flexible program can be created.

- To make phone calls and video chats with relatives, family and friends who cannot be seen because of social distance. Hence, people can have the feeling that social life continues in another form.

As we see, the negative psychological effects of pandemic may appear. According to this we can see that informing people constantly, about hygiene, and sharing the information about pandemic cases and treatment methods and results help reduce public anxiety. In addition, since everyone is isolated in their own home in this process, presenting thoughts that will encourage people to cooperate and act together and create common feelings and motivation among people reduces social uncertainty and anxiety.

Important effects of a pandemic are the curfew and isolation of people. People feel lonely at home and alienated due to diminishing social interaction. Apart from the reactions to the epidemic, the responses to uncertainty and the ability to cope with stress, depending on the personality structure, person-to person, age (childyoung-adult-elderly), socio-economic and cultural situation, etc. can also vary depending on many other factors.

A common behavior we see in outbreaks is that we move away from rational solutions and quickly believe some myths spread through social media. Hearing unscientific comments and information pollution can cause a lot of fear in humans. Therefore, people should be informed frequently by the authorities. Repetition of the measures, the rational dimensions of the Corona virus outbreak, and the high 
morale of people are extremely important for success. These problems are leading all individuals and communities to the atmosphere of risks to which they cannot be immune and that they cannot foresee and control in any way. During this crisis caused by the pandemic, it is essential for governments and state institutions to manage the discourse and actions, viewpoints of events and ways of directing the society, which are very important for them to effectively manage the crisis process. At this point, the concept of value-based collaboration emerges.

Understanding cooperation means understanding how members use the language to share specific things. Organizational reality is thus created by using these language games. Understanding cooperation also denotes understanding the life structures of people inside organisations and how they influence the way members address and solve problems as well as how they are generally involved in organisational life (Jørgensen, 2004: 88).

Wittgenstein's concept of language games suggests that the positions, interests, intentions and strength of language games are described using Foucault's concept of power (Foucault, 1978, 1979 qtd in Jørgensen, 2004: 86). When used from a critical point of view, it is useful to emphasize how a certain change in discourse creates problems, methods and solutions that contain some specific ideas about who people are and why they think and do what they do (ibid). In Wittgenstein's conception, languages become a part of life and doing things essentially a part of everyday life. The meaning of language is understood by the work that the language is doing in social life.

According to Ethics Resource Center, value driven activities are defined by guiding principles, mission statements, moral standards for leadership, motivating people for value commitment (qtd in Wieland, 2005). During the process of the pandemic, the Turkish Minister of Health explained the principles and rules necessary for circumventing the pandemic and stated the rules and duties that each individual should do and follow individually on his Twitter account. In this process, he put forward the motivations that enable people to act together in cooperation with each other without alienation and invited people to contribute to the circumvention of the process. In this sense, we can see the performance of a value-driven activity. Society is a system like an organization and social practices are carried out within this system. Like many others, Turkey is a society that makes collective decisions and reveals it through collective discourse and practices with a related self-structure. In such a cultural structure, people do not become alienated from each other. For example, the various slogans put forward during this pandemic are; "stay at home," "we are good enough for us" etc. These statements have led people to act together. All in all, physical isolation was attempted to be overcome with emotional and intellectual integration.

Groddeck (2010: 70-71) discusses that all social systems encompass certain communication operations or rather the interconnection of communication events over time. The term "system" is employed to display how certain social formations are generated, which are stabilised by mutual relations, feedback and selfmanagement processes.

The term value has a long tradition in sociology, philosophy and economics. It grew very prominent at the end of the $19^{\text {th }}$ century, when early sociologists used it to 
discuss the question of societal integration. Because of an increasingly differentiated society with a less clear structure, the question arose as to what the society was holding together. The answer was seen in moral, social and cultural values, not in religious beliefs, as it was in the pre-modern society (Durkheim, 1973; Parsons, 1960 qtd in Groddeck (2010: 72). Talcott PARSONS formulates: "Values in this sense are commitments of individual persons to pursue and support certain directions or types of action for the collectivity as a system and hence derivatively for their own roles in the collectivity."

Values are not considered a fundamental condition for individuals or social entities that affect effectiveness. These are empirically observable forms of communication that show values only as invisible aspects of individuals or social entities and are evaluated as values by empirical applications, for example, by referring to corporate values, ethical standards, value learning programs to improve leadership skills, or just expressing the values, beliefs and drivers of managers. A specific phenomenon as a form of value communication is perceived as an operational solution to an operational problem in the organization. From a systemic theoretical point of view, the relationship between problem solving is based on the need for survival of the system that is organized here. If we ask for a function of value communication, the task will be dealt with by addressing value communication with the application and dealing with a specific reference issue and the phenomenon of value communication. The uncertainty of solving a complex organization and its surroundings can be treated as semantics through value communication. Values are an environment in which organizations can inevitably cope with the uncertainty that creates the synchronisedness of a large number of enterprise operations (ibid, pp. 74-76).

Value-based communication should be addressed more in the context of healthcare within the scope of this study. In this context, we should first define value in the context of value-based healthcare.

The concept of "value-based healthcare (VBHC) is getting more commonly used in public debate and the notion of "value" is frequently considered as "health outcomes related to realised inputs." Nevertheless, two important aspects must be taken into account (European Union, 2019):

1. European healthcare systems are based on the concept of solidarity. The Charter of Fundamental Rights of the European Union and the European Pillar of Social Rights secure universal access to affordable, preventive, curative and good quality healthcare in the EU.

2. There is no single definition of 'value' within value-based healthcare. The definition of value is subjective and what is considered valuable can differ between patients, clinicians, healthcare providers, policy makers or industry stakeholders.

In order to meet the challenge of ensuring the financial sustainability of universal healthcare and finding the resources to finance innovation, it is essential to switch resources from a lower value to higher value healthcare. The Expert Group proposes a comprehensive concept based on four value pillars to define 
"value-based healthcare" to convey the guiding principles of solidarity-based healthcare systems (ibid, p. 1).

Allocative Value: Equitable distribution of resources across all patient groups. Technical Value: Achievement of best possible outcomes with available resources.

Personal Value: Appropriate care to achieve patients' personal goals.

Societal Value: Contribution of healthcare to social participation and connectedness.

Value-based healthcare can be used to inform when deciding and contributing to the streamlining, availability and resilience of healthcare systems. Initiatives have now been undertaken to address the following areas:

- Reallocation of resources: Disinvestment for reinvestment Unwarranted variation defined as 'variation in the utilization of healthcare services that cannot be explained by variation in patient illness or patient goals'.

- Fighting corruption, fraud and misuse of public resources.

- Increase public value in biomedical and health research.

- Regulatory policies for better access to high-value (but costly) medicines

- Incentives for fairer distribution and more optimal use of resources (ibid, p. 1).

The Expert Panel (Expert Panel's Recommendations) understands the redistribution of care from low to high value as the highest necessity for sustainable and resilient European health systems. A long-term strategy is recommended to achieve a cultural shift that allows for the release of resources to re-invest in highvalue care and to effectively redistribute towards value-based health care, with a strong management system.

- Develop a long-term strategy for a step-by step value-based approach towards change of culture. This strategy should encompass the definition of a series of goals that support the long-term objective of change, moving forward in small steps (work plans), including the implementation and monitoring of effects by use of existing data sources and methodologies as well as the creation of mechanisms to further guide the direction of change towards high value care.

- Support Research \& Development on/of methodologies on appropriateness and unwarranted variation by exchanging robust methodologies for measuring and monitoring patterns of clinical practice, regional variation, appropriateness research, by stimulating data collections (incl. real world evidence and big data) and by defining and aligning goal-oriented outcomes that matter to patients.

- Encourage health professionals to take responsibility and feel accountable for increasing value in healthcare, which may require freeing resources from low-value care to reinvest in high-value care encompassing the 
training of "change agents" (leaders) that feel accountable for the health of the population, including equitable distribution of resources across diseases. Health professionals hold a key role in advocating a change of culture towards social cohesion and connectedness.

- Support the creation of Learning Communities, including communities of health professionals, to bring together the best expertise, experiences and practices, contribute to change of attitudes and to learn from each other by measuring, benchmarking and implementing actions across the EU. Member States should take the lead in identifying and pinpointing the most important tasks, the EC should create a supportive and facilitating environment for the establishment of those Learning Communities that will contribute to a change of behaviour and a change in legislation.

- Support initiatives for patients' engagement in shared decision-making, recognising the importance of patients' goals, values and preferences, informed by high quality information to implement empowering practices and goal-oriented person-centred care (ibid, p. 2).

\section{Community Building Function of Social Media in the Context of Twitter}

Developments such as the spread of the internet, the ability of individuals to interact and produce their own content on the internet have had important effects on the structure of communication. With the digitalization, changing the production, distribution, display and storage facilities of the media and transferring cultural products to the digital environment affect culture; transform all stages of communication. Trends such as increased interaction with social networks and the ability of the user to contribute to content production have not only led to the emergence of new forms of communication, but have also affected the consumption and production patterns of traditional media. In this context, Lev Manovich states that new cultural forms are emerging and cultural forms such as photography, television and cinema are being transformed and redefined. The ability of internet users to produce content in virtual environments, to share their comments, opinions, as well as the traditional media's one-to-many communication structure, have enabled the development of communication structures between peers, from one person to one, from many to many (Ateşalp and Başlar, 2015).

Henry Jenkins (Jenkins and Deuze, 2008) defines the change in communication environment through the concept of convergence. The phenomenon of convergence in the communication environment is more than just a technological change; it is a complex process with economic, global, social and cultural dimensions. Jenkins uses the concept of convergence to define content streaming across multiple media platforms, to collaborate across multiple media industries, and to immerse viewers who can migrate anywhere. Convergence points to a cultural shift that encourages consumers to seek new information and to make connections between scattered media content.

As a result of the rapid developments in computer technologies and communication networks, the internet has become an indispensable part of our lives. The process, which we call the technological paradigm by Castells (2008), 
radically changes almost every aspect of our lives such as economy, politics, social relations, and culture. The technological paradigm has revolutionized almost everything in the context of time, space and relationships, and it has created new patterns of perception and relationship. This transformation that the technological paradigm has revealed in social structures and movements has led to the expression of the society we live in as a "network society". This type of society, which is referred to as the network society, has started to transform the society structures by spreading to a very large part of the world very quickly unlike the previous society types (Castells, 2008). The internet, which was used only as a means of getting information and accessing information for the first time, has become a social communication tool with the widespread use of websites such as Facebook, Twitter, etc. which have been defined as social media, and continuous communication at home, at work, on the street in short, almost everywhere where human beings exist. It created a virtual society. The relationships and actors envisaged by the classical sociology for the social structure have now started to change size and function (Köseoğlu and Al, 2013).

While social media has an increasingly larger place in social life, it is also important for brands, non-governmental organizations and politicians. Brands, non-governmental organizations and politicians use social media for public relations. However, social media is considered as a public space and politicians use social media as a communication tool within the framework of public relations. Political parties, leaders or candidates generally use social media tools in order to provide information, increase voting rates by affecting voters' behavior, preferences and decisions, create resources, create information networks with internal and external groups, and increase political participation.

\section{Methodology}

\section{Purpose}

This study aims to analyze the reflection of the communication strategy concerning the global Covid-19 crisis, utilized by The Turkish Minister of Health, on the discourses on Twitter. This analysis will be based on Value-Based Communication. In addition, word relation matrix and cluster analysis were performed using data mining methods.

It should be pointed out that the healthcare communication about Covid-19 has been managed and thus the data shared by the Minister of Health all by himself. Therefore, there has not been a secondary data sharing or pronouncement about the respective pandemic by any other government organisations or institutions.

At this point, it might be helpful to provide brief definitions of description, analysis and interpretation. Firstly, description is highlighting what the data collected indicates and what results it produces according to the research question. Analysis; on the other hand, is uncovering the themes and meaningful relationships between these themes that are not seen directly in the data set through conceptual 
coding and classification. Descriptive analysis consists of four stages (Y1ldırım and Şimşek, 2018):

1. Creating a framework for descriptive analysis.

2. Processing the data according to thematic framework.

3. Identification of findings.

4. Interpretation of findings.

The question of "what a particular utterance or observation indicates" draws up the main function of interpretation. In data analysis, meaning comes to the fore. Highlighting the meaning depends on the interpretation of the findings within their environment (ibid.). Furthermore, Miles, Huberman and Saldana (2014) categorise the four the components data analysis as; data collection, data display, data condensation and conclusion: drawing / verifying.

According to the visual analysis approach; collected data is summarized and interpreted according to the previously determined themes. Data can either be edited according to the themes put forward by research questions or may be presented by taking into account the questions or dimensions used in interview and observation processes (Yıldırım and Şimşek, 2018). Moreover, discourse analysis is the examination of the language in use, which is an approach to the analysis of any semiotic event (Gee, 2014).

\section{Limitations}

Twitter API has some restrictions on pulling data from user profiles. One of the restrictions is that it can only receive 3200 tweets per day. Another limitation is that some tweets in the date range can be skipped during this process. Although the study universe has 505 tweets in this research, this number may be different for the reasons mentioned above.

\section{Universe and Sampling}

In this study, it is determined that the first tweet by the Ministry of Health regarding Covid-19 was posted in 25.01.2020. It was seen that 505 tweets were posted during this process. Purposeful sampling method was used to measure the Value-Based Communication of the Ministry of Health. "Purposeful sampling allows for deep study of situations that are considered to have rich information" (Yıldırım and Şimşek, 2018: 118). In the "Value-Based Communication" analysis of the study, the first 100 tweets of the Minister of Health that had interaction were taken as basis and the codings were made through these tweets. The parameters used in the interaction of tweets are specified as: "retweetCount $=$ count of retweets" and "favoriteCount = count of likes". The interaction rate was determined by taking the arithmetic average of these parameters. The tweets that had the most interaction are revealed utilizing the formula below. 


\section{retweetCount favoriteCount \\ Interaction Rate:

All of the 505 tweets were used for the word proximity matrix and cluster analysis on the discourses of the Minister of Health on Twitter. Descriptive research model (Yıldırım and Şimşek, 2018: 239) was used as the method in the study. Mixed research designs are also included in the research by using qualitative and quantitative methods together. A Twitter Developer Account was created to obtain the data. An API (Application Programming Interface) was acquired from Twitter to obtain the data. All tweets were obtained using the RStudio program via the API. With the same program, tweets were converted into data frame/tibble data format and made ready for analysis.

The purpose of this discourse analysis is to highlight the hidden content that is not visible at first glance. During the analysis, evaluations were made over the words that came to the fore according to the frequency ranges of the words. In this analysis, in cases where the same word differs by taking a suffix, they are combined as a single word. In addition, synonyms have been subjected to the same process.

Codings were performed on the NVivo 11 Pro program. The coding process was carried out manually by the authors of the article. Firstly, for the coding reliability, each researcher performed an individual coding process on the related data set. Pre-coding on the data set was evaluated by all researchers, and a specific coding system was created. In order to ensure the validity of the coding process and to reduce errors, the message classifications are set to certain standards. Content not relevant for the study is excluded from the coding process. All operations, analysis, and data visualization techniques, except for coding on text with NVivo, were done with the RStudio program.

Text mining is another approach used in this study. Text mining can simply be defined as the process of producing structural texts that contain information from large amounts of unstructured texts. In order to reveal meaningful expressions with the processing of texts, some steps such as data preprocessing and feature extraction should be performed. After these stages, the non-structural data are converted into a structural format for the use of the text mining method. In this way, meaningful information in large amounts of data is tried to be revealed. By using these meaningful data, various results can be reached that institutions or organizations will benefit from. Mathematical and statistical methods are on the basis of text mining methods. Text mining is also used in different areas such as author recognition, text classification, idea mining, emotion analysis, keyword extraction, natural language processing, title extraction, and relationship rule extraction (Kılınç et al., 2016).

In the study, text processing and analysis were done with the RStudio program. The text mining library included in the RStudio called "Text Mining Package" or "TM" was used. The following text mining processes were applied respectively. Converting data into a corpus, equalizing the text size (tolower), removing punctuation marks (removePunctuation), removing numerical expressions 
(removeNumbers), removing expressions such as conjunctions and prepositions (removewords stopwords: 'Turkish') -when clearing these words, a dictionary appropriate for the language used should be selected-, removing internet links (removeURL), removing unnecessary words as deemed by the author in accordance with the study (removewords), combining words that can mean the same to one word (e.g., İstanbul and İstanbul'da), and removing word spaces (stripwhitespace). Finally, with the "TermDocumentMatrix" function, a termdocument matrix has been created for the data set received from the tweets. In this matrix, all words are converted to values 0 and 1 and network diagrams of words are created. Finally, cluster analysis was performed with the "cluster_fast_greedy" algorithm in RStudio.

\section{Results}

Top 100 tweets of Health Minister with the most interaction regarding Covid19 were examined. In total, 782 codings were carried out. These codings include three main categories of Value-Based Communication and their sub-categories. The main categories are "trust", "person-oriented health actions" and "governance". The "trust" category has 7 sub-categories, "person-oriented health actions" has 10, and "governance" has 4 sub-categories. There are 21 sub-categories in total.

In the codings made according to the expressions on Twitter (Table 1), it was determined that there were 266 codes in the "trust" category, 337 codes in the "person-oriented health actions" category, and 179 codes in the "governance" category. In this value-based coding, it has been determined that expressions about "person-oriented health actions" come to the fore with $43.1 \%$. Secondly, it was revealed that the expressions about "trust" were at $34.0 \%$, and finally the "governance" category at $22.9 \%$. As we can see, person-oriented health actions take precedence, and the qualifications that should be in people-centred care are as follows: social value, meeting needs, informing patients, doctors and public about the pandemic, qualified health workers, rapid intervention, personal and technical values, distribution-based value and research.

Table 1. Main Categories

\begin{tabular}{|l|c|c|}
\hline \multicolumn{1}{|c|}{ Features } & Frequency & Percent (\%) \\
\hline Trust & 266 & 34.0 \\
\hline $\begin{array}{l}\text { Person-Oriented Health } \\
\text { Actions }\end{array}$ & 337 & 43.1 \\
\hline Governance & 179 & 22.9 \\
\hline
\end{tabular}

The other important element that emerges is governance. In this respect, governance value is part of the value based management which offers a holistic solution to achieve performance, focusing on three core components:

- The main objective of maximising value through the implementation of sustainable strategies. 
- The management of the value which focuses on factors related to the attainment of the primary objective, factors relating to management, organizational culture, communication, relations with the external economic.

- Social and natural environment; Performance assessment system indicators that reflect the creation of value (Oane et al., 2015: 107).

The third important finding is an element of trust. In other words, building trust between management and the public is significant. Here are seven tips for managers to build or rebuild trust introduced by Sabatier (2014: 3-5):

1. Take an inventory of your trustworthy behaviours.

2. Act with integrity.

3. Admit mistakes.

4. Straight talk: do not avoid difficult conversations or feedback; people have the righ to know what you think.

5. Be approachable.

6. Right wrongs and go the extra mile.

7. Hold people accountable: People need to understand the benefits and consequences of their actions or lack of them.

Firstly, when looking at the "trust" factor (Table 2), the prominent features are "continuous information" with $9.3 \%$ and "reciprocity" with $9.0 \%$. (The numbers were shared daily with the daily number of cases in order to prevent a crisis and panic in the public.) The next features that were determined are, "interaction" with $5.9 \%$ (interaction with the scientific board, patients, artists' posts about Covid-19) and "assuming responsibility" with 3.7\% (the minister of health assumed responsibility for the problems that arose). The least common "trust" features among the content used by the minister on Twitter were found to be "prioritizing quality" with $1.9 \%$ and "compliance with ethical standards" with $1.5 \%$.

In the second factor, "person-oriented health actions" category, the most dominant features are as follows: "social value" with 10.7\%, "meeting needs" with $8.3 \%$, "informing patients, doctors and the public about the pandemic" with $6.6 \%$ and "personal value" with $6.1 \%$. Other distributions emerge as "qualified health workers" with $2.6 \%$, "rapid intervention" with $2.3 \%$, "technical value" with $1.9 \%$, "early diagnosis" with $1.5 \%$, "distribution-based value" with $1.5 \%$, and "research" with $1.4 \%$. As seen, person-oriented health actions, social value, meeting needs and informing patients, doctors and the public about the pandemic as well as personal value emerge as the prominent factors. In this context, within the scope of the statements made on Twitter, it is seen that the expectations and needs of the public are taken into account and that the functions performed are fulfilled in accordance with these expectations and information is given. This indicates a necessity to enhance the capacities of hospitals, to acquire new technical tools needed, to increase the number of beds and breathing apparatus, and to provide continuous information about pandemic. 
Table 2. Sub-Categories

\begin{tabular}{|l|c|c|}
\hline \multicolumn{1}{|c|}{ Features } & Frequency & Percent (\%) \\
\hline Trust & 21 & 2.7 \\
\hline Dialog & 12 & 1.5 \\
\hline Compliance with Ethical Standards & 46 & 5.9 \\
\hline Interaction & 15 & 1.9 \\
\hline Prioritizing Quality & 70 & 9.0 \\
Reciprocity & 29 & 3.7 \\
Assuming Responsibility & 73 & 9.3 \\
Continuous Information & 11 & 1.4 \\
\hline Person-Oriented Health Actions & 12 & 1.5 \\
\hline Research & 12 & 1.5 \\
\hline Distribution-Based Value & 52 & 6.6 \\
Early Diagnosis & 18 & 2.3 \\
Informing Patients, Doctors \& the Public & 65 & 8.3 \\
About the Pandemic & 48 & 6.1 \\
Rapid Intervention & 20 & 2.6 \\
Meeting Needs & 84 & 10.7 \\
Personal Value & 15 & 1.9 \\
Qualified Health Workers & \multicolumn{2}{|l|}{} \\
Social Value & 57 & 31.8 \\
Technical Value & 15 & 3.4 \\
\hline Governance & 55 & 29.1 \\
\hline Openness & 52 & \\
\hline Accountability & \multicolumn{2}{|l|}{} \\
Participation of Stakeholders in the Process & \multicolumn{2}{|c|}{} \\
\hline Transparency & \multicolumn{2}{|c|}{} \\
\hline
\end{tabular}

Figure 1. Content Based Communication Categories

Content Based Communication

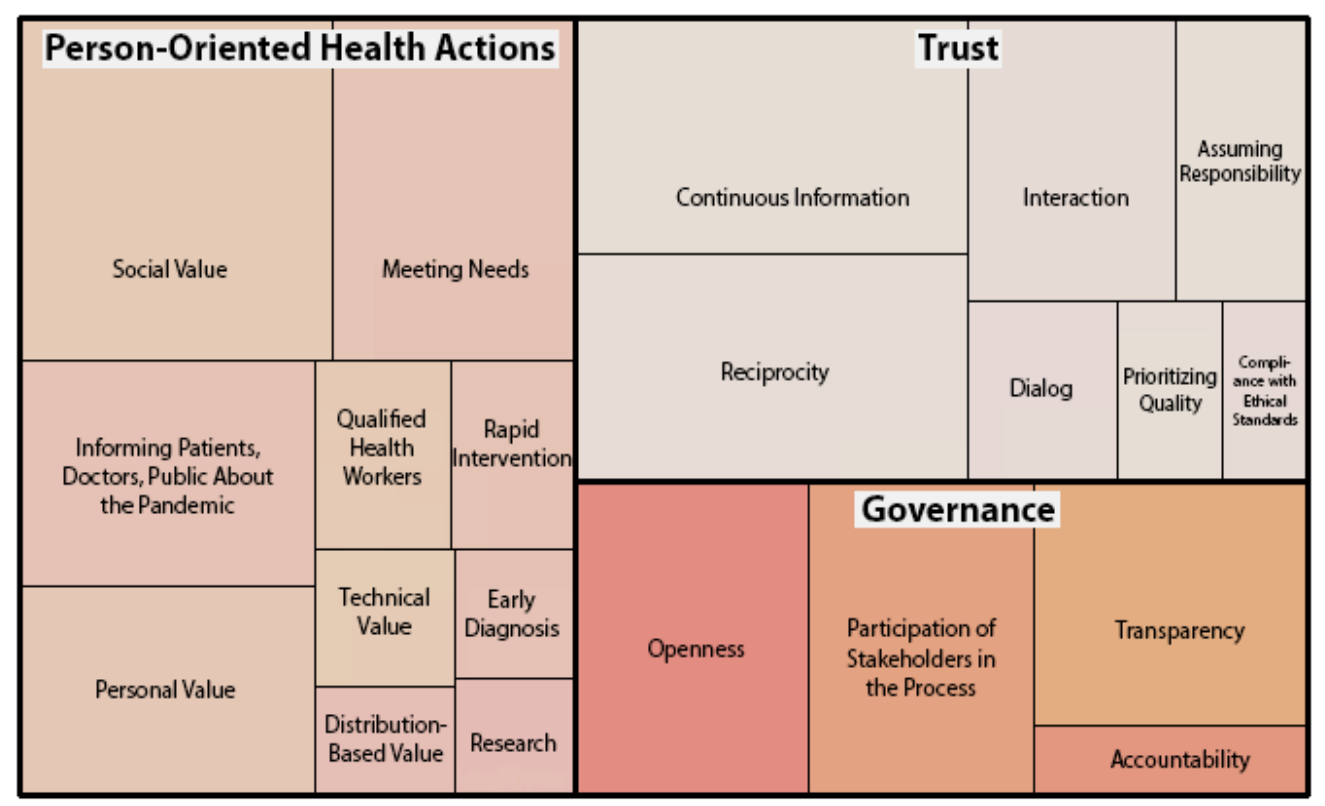


In the last factor, the "governance" category, the sub-category distribution rates are determined as "openness" with $31.8 \%$, "participation of stakeholders in the process" with $30.7 \%$, "transparency" with $29.1 \%$ and "accountability" with $8.4 \%$. The distribution of categories and sub-categories is shown descriptively in Figure 1.

Figure 2. Word Relationship Matrix based on the Twitter Discourse Analysis of the Turkish Minister of Health about Covid-19

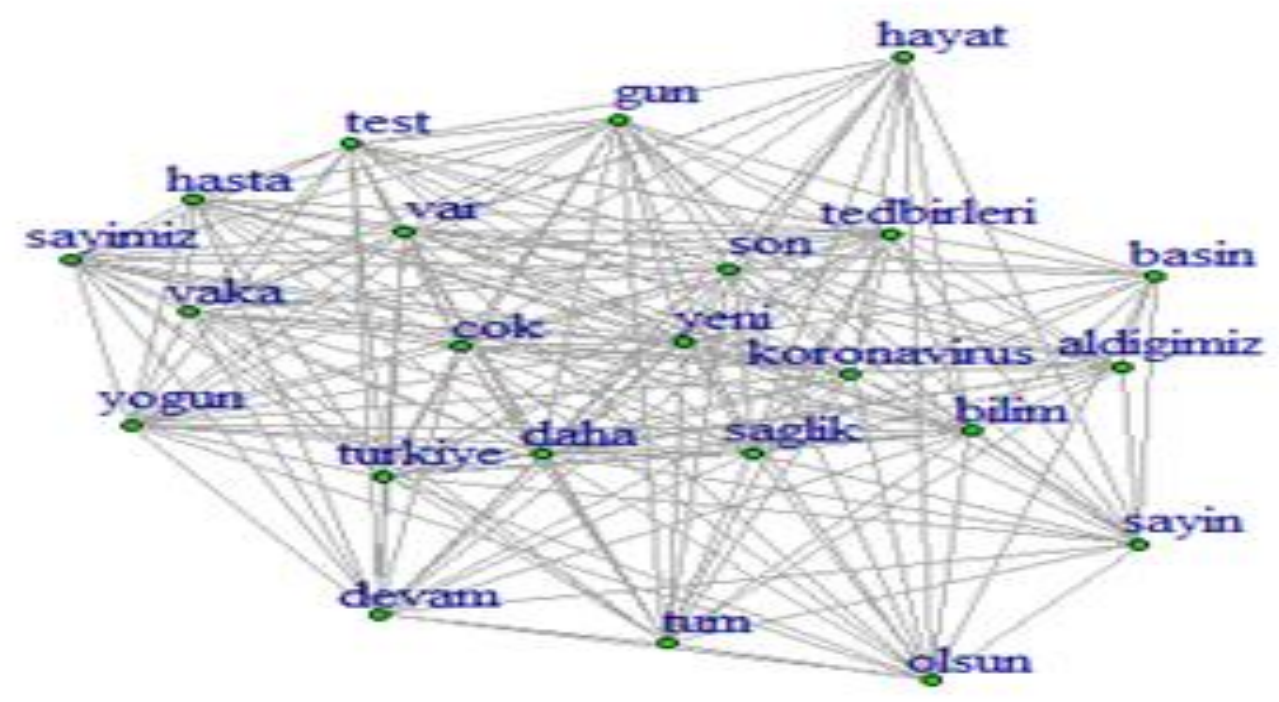

Figure 3. Cluster Analysis based on the Twitter Discourse Analysis of the Turkish Minister of Health about Covid-19

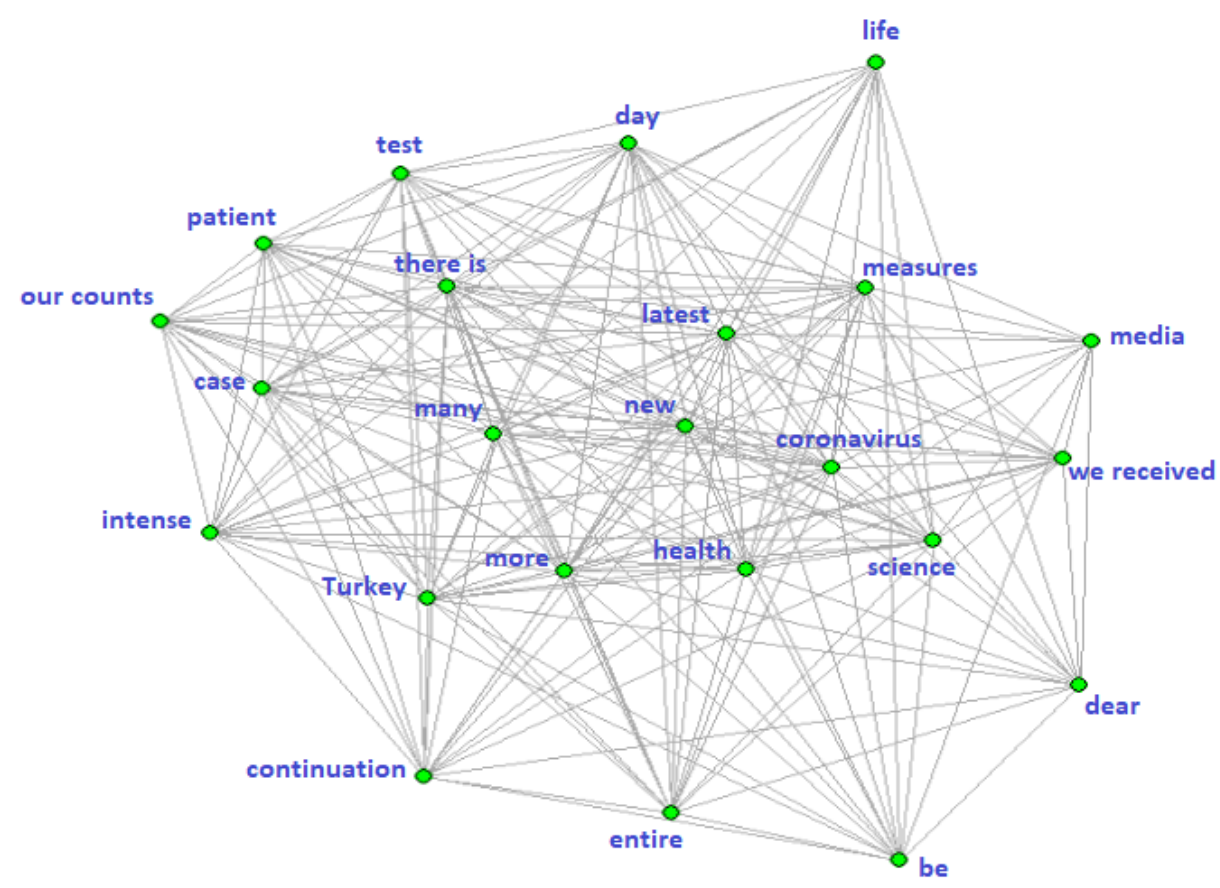



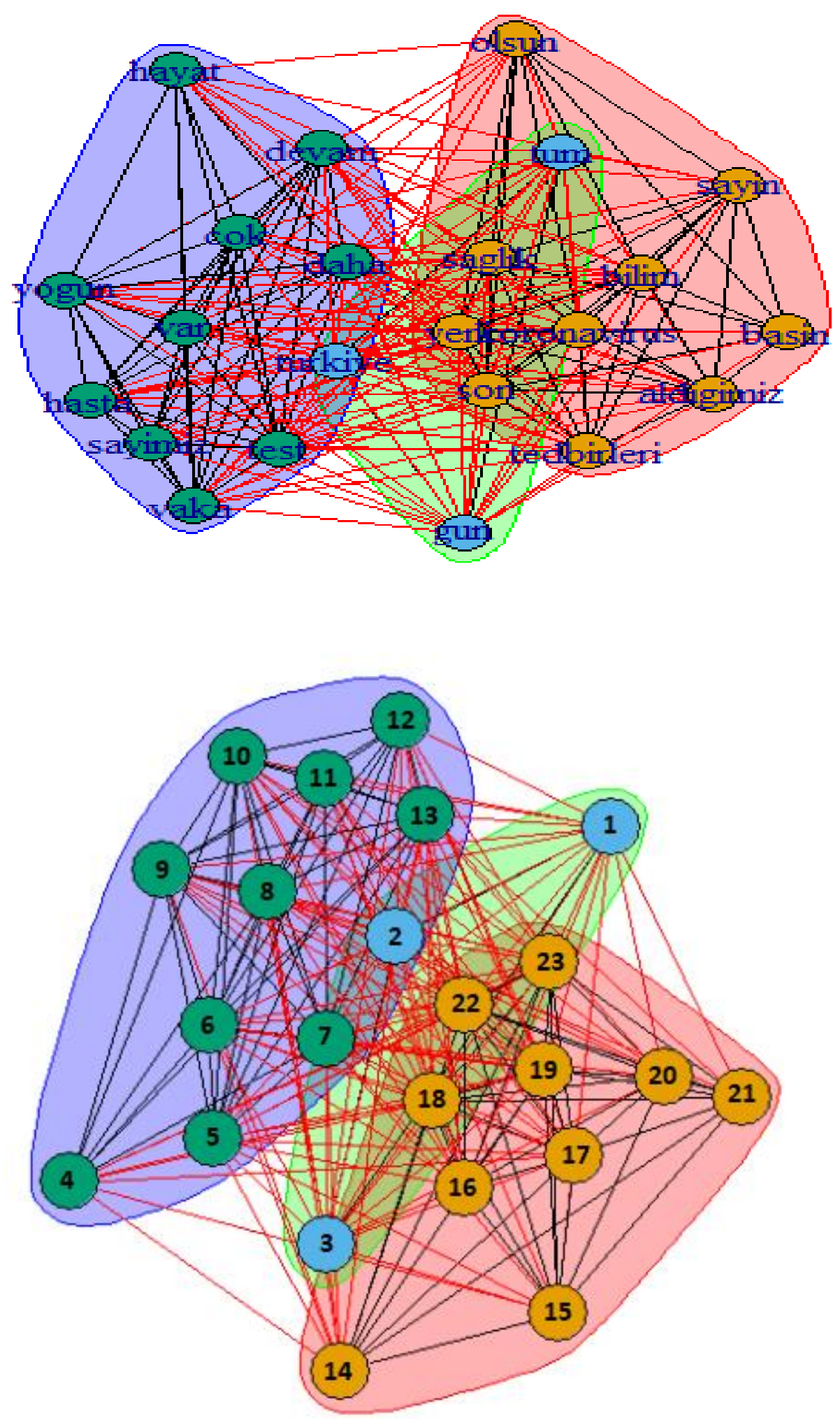
$\underline{\text { Blue }}$

1- Day

2- Turkey

3- All

Green

4- Life

5- Continue

6- Many

7- More

8- There is

9- Intensive

10-Case

11-Patient

12-Number

13-Test

$\underline{\text { Yellow }}$

14-Let there be

15-Dear

16-Precautions

17-Science

18-Health

19-Coranavirus

20-The (precautions) taken

21-Media

22-New

23-Last

\section{Discussion}

Leaders try to create some behavior in the audience with the way they communicate, while trying to create understanding and relationships with the target audience. There are elements such as mutual dependence, satisfaction, empathy and trust in this relationship.

Satisfaction with communication seems to be more associated with communication focused on tasks such as relationship-based communication, because task-oriented communication is immediately rewarded by executing a task. As people focus more on remote communication than for personal communication, it is expected that, compared to communication to building relationships, communication focused on tasks shows a greater impact on satisfaction with communication (Marshall \& Novick, 1995 qtd. in Kang, Han \& Lee, 2017). Successful communication affects cooperation. Task-oriented and relationshipbuilding communication consists of interdependencies, joint management and satisfaction with communication (ibid, p. 5). 
Moreover, Bennis and Thomas (2002: 1-2) maintain that leaders create a sense of events and relationships that would otherwise go to waste without them. Even if the leaders are bothered by experience; they are not considered helpless and are not considered paralyzed. They look at the same events that encourage those less capable and happy, and see something useful and often a plan of action. An important part of our leadership model is what lies on the other side of the crucible-qualities that define lifelong leaders and learners. One of the main advantages that all our leaders share, whether young or old is their ability to adapt. The ability to process new experiences, find their meaning and integrate them into a person's life is the ability to designate leaders and truly anyone who finds ways to live fully and well.

On the other hand, Stein et al. (2013) assert that there is still a large transformation of people-to-human care services: the lack of clearly defined and measurable objectives, consistent communication strategies or participatory approaches in the development and implementation of integrated care are only a few shortcomings that can lead to partial shortcomings that may give way to optimal results or current challenges with a view to sustainable and large scale efforts. Ensuring implementation throughout the system often prevents ambiguous stimulus structures, the lack of suitably trained professionals and/or obsolete legal frameworks.

Quality movement and ergonomic movement have many basic similarities, such as the basic values on which these movements are built. The keywords shared between them are; "Human needs, expectations, requirements, comfort, health, happiness and satisfaction" (Axelsson qtd in Bäckström et al., 2014: 59).

Furthermore, as Bäckström et al. (2014, pp. 61-62) indicate, communicative leadership can be defined as openness, accountability and continuous dialogue with communities. Communicative behaviours of leaders encompass four aspects: "structuring, facilitating, relating and representing" Furthermore, engaging communities in dialogue, actively sharing and seeking feedback, giving importance to participative decision making.

Within the scope of this study, it can be stated that through Twitter, the number of pandemic-related deaths, the number of positive and negative issues, the developments in the health prompt, comparative rates of cases with different countries, treatment methods applied, research on vaccine, etc. have constantly been emphasized. In the same way, the issues such as openness, transparency and reliability have been stressed.

\section{Conclusion}

The beginning of pandemia communication is March 11, 2020, when the first Covid-19 case was announced, as in measures and combat. The Minister of Health has come to prominence in the disclosure of the measures taken since then and informing the public about developments in Covid-19 cases. It has been the right choice of communication on behalf of the government to assume that the Minister of Health is predominantly in the name of the government to announce information 
about pandemic to the public. The Minister of Health initially began making a statement from his Twitter account towards midnight, making the number of cases and deaths public (Türk tabipleri birliği - Covid-19 pandemisi iki aylik değerlen dirme raporu, p. 54).

Health care workers were applauded by the public every evening at $9 \mathrm{pm}$ to support health care workers during pandemics and to create a respect and appreciation for their service. In this way, it has been positive for providing moral support to health care workers. It has been through Twitter to receive this support from the public.

Daily statements about pandemics, which are regularly performed by the Health Minister, have become more organized since March 27, 2020. The tweets, which he went through towards midnight, were replaced by a press conference two days a week after science board meetings and table statements covering information such as new cases, test numbers, recovery and deaths (p. 55). It can be suggested that the health minister, as a leader, managed the pandemic crisis with appropriate communication within the general action plan.

It should also be mentioned that the communication carried out by the Minister of Health is generally a task-oriented communication. The Ministry of Health's communication via Twitter has been made to the idea of which words are most used, the relationship of words to each other and in which clusters they are gathered within the context of idea mining. This review is based on the main criteria and sub-criteria of value-based communication. In the network diagram analysis (Figure 2), it is aimed to show the relation density of the words with each other. The center of this network diagram is created by "health", "coronavirus", "science", "new", "end", "measures", "case", "have" and "Turkey" words. It is determined that other words are used frequently together with these words in the center. It is seen that the other words associated with the words in the center are, "life", "test", "patient", "our number", "intensive", "continuation" and "day". Finally, it was determined that the word matrix created in the cluster analysis (Figure 3) is divided into three clusters. It is seen that these clusters are in parallel with the three basic categories of Value-Based Communication. Lilac colored area can be said to represent the main category of "trust". The words "patient", "test" and "our number" match with the category of "continuous information". Rose color, on the other hand, can be said to be closely related to "person-oriented health actions". The words "we take", "measures", "coronavirus", "science", "health" can be interpreted together with "social value", "meeting needs", "personal value". It can be said that the green color is representing the "trust" main category with the words "all" and "Turkey".

There is also a similarity between the elements of value based communication and the elements of quality management value. Considering all these respected elements, we need to have a management approach that meets communicative leadership features.

It is seen that communication activities performed during the pandemic are carried out in accordance with communicative leadership. It is more difficult to convince and direct people due to anxiety and ambiguity seen in society during the pandemic process. To eliminate this anxiety and uncertainty, a persuasive 
communication must be applied in it carrying some regulations and collaborations and various rules. This value-based collaboration will make it easier to manage the crisis process. Within the scope of this study, the rhetorical elements that create value-based communication are taken into account. These rhetorical elements are the main and sub-criteria that makeup value-based communication. With this rhetoric, value-based collaboration can be created as a new form of governance. Some procedures, norms and standards are applied to control this collaboration. In this sense, collaboration enables the establishment of communication between people in everyday life practices to create mutual understanding between people. Value-based communication demonstrates personality focus, sustainable communication, trust and clarity. Within the scope of this study, it can be said that messages provided by the Minister of Health via Twitter are in line with the main criteria and sub-criteria of value-based communication and constitutes collaboration.

\section{References}

Ateşalp, S. T., Başlar, G. (2015). Debates on participatory culture in relation to TV dramas in social media: Kardeş Payı case. E-Journal of Intermedia, 2(1), 158-180.

Bäckström, I, Ingelsson, P., Johansson, C. (2014). Health related quality management values and key principles of communicative leadership - Are they the same? Quality Innovation Prosperity, 18(1) 59-72.

Bahadır, G. (2020). Pandemi sürecinin psikolojik etkileri virüs kadar hızla yayılıyor. (Psychological effects of the pandemic is spreading as fast as the virus). Retrieved from: https://bit.ly/2FbJ3RC. [Accessed 2 May 2020]

Bennis, W. G., Thomas, R. J. (2002). Geeks and geezers: how era, values, and defining moments shape leaders - How tough times shape good leaders - Working knowledge for business leaders. Retrieved from: https://hbs.me/3bzueUV 8. [Accessed 5 May 2020]

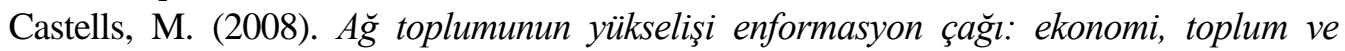
Kültuir. (The rise of the network society, information age: economy, society and culture). Turkey: İstanbul Bilgi Üniversitesi Yayınları.

Çoban, A. (2020). Koronavirüs salgınının psikososyal etkileri. (Psyho-social effects of corona pandemic). Retrieved from: https://www.cnnturk.com/saglik/koronavirussalgininin-psikososyal-etkileri. [Accessed 18 March 2020]

European Union (2019). Defining value in "value based healthcare". Report of the Expert Panel on Effective Ways of Investing in Health (EXPH). Luxembourg: Publications Office of the European Union.

Gee, J. P. (2014). How to do discourse analysis. London: Routledge.

Groddeck, V. (2010). The case of value based communication-Epistemological and methodological reflections from a system theoretical perspective. Forum Qualitative Sozialforschung, 11(3).

Jenkins, H., Deuze, M. (2008). Convergence culture. Convergence: The International Journal of Research into New Media Technologies 14(1), 5-12.

Jørgensen, K. M. (2004). Creating value-based collaboration: life forms and power in a change project.M@n@gement, 7(3),85-107.

Kang, I., Han, S., Lee, J. (2017). Task-oriented and relationship-building communications between air traffic controllers and pilots. Sustainability. 9(10), 1-16. 
Kılınç, D., Borandağ, E., Yücalar, F., Tunalı, V., Şimşek, M., Özçift, A. (2016). KNN Algoritması ve R Dili ile metin madenciliği kullanılarak bilimsel makale tasnifi. (Scientific article categorisation with the use of $\mathrm{KNN}$ algorithm and $\mathrm{K}$ language). Marmara Fen Bilimleri Dergisi, 28(3), 89-94.

Köseoğlu, Y., Al, H. (2013). Bir siyasal propaganda aracı olarak sosyal medya (Social media as a means of political propaganda). Akademik Incelemeler Dergisi, 8(3), 103125.

Miles, M. B., Huberman, A. M., Saldana, J. (2014). Qualitative data analysis - A Methods sourcebook. London: SAGE Publications Ltd.

Oane (Marinescu) C.M., Smolag K., Marinescu E.S., Szopa R. (2015). Value-based management as the innovating paradigm of contemporary governance - A theoretical approach. Polish Journal of Management Studies, 12(1), 106-120.

Sabatier, M. (2014). As a leader are you trustworthy? Building trust to transform team working. Development and Learning in Organizations, 28(5), 3-5.

Stein, V., Barbazza, E., Tello, J., Kluge, H. (2013). Towards people-centred health services delivery: a framework for action for the World Health Organisation (WHO) European region. International Journal of Integrated Care, 13(4), 1-3.

Szecsi, G., Koller, I. (2017). Community and morality in the digital age. Coactivity: Philosophy, Communication, 25(1), 18-25.

Türk tabipleri birliği - Covid-19 pandemisi iki aylik değerlendirme raporu. (Turkish medical association - bimonthly evaluation report). Retrieved from: https://www.ttb. org.tr/userfiles/files/covid19-rapor.pdf. [Accessed 28 April 2020]

Wieland, J. (2005). Corporate governance, values management, and standards: a european perspective. Business \& Society, 44(1). 74-93. 10.1177/00076503052748 52.

Yıldırım, A., Şimşek, H. (2018). Sosyal bilimlerde nitel araştırma yöntemleri. (Qualitative research methods in social sciences). Eskişehir: Seçkin.

Zhang, Y., Ma, Z. F. (2020). Impact of the COVID-19 pandemic on mental health and quality of life among local residents in Liaoning Province, China: a cross-sectional study. International Journal of Environmental Research and Public Health, 17(7), 112 . 